\title{
VARIABILIDAD CLIMÁTICA Y RIESGOS CLIMÁTICOS EN PERSPECTIVA HISTÓRICA. EL CASO DE CATALUNYA EN LOS SIGLOS XVIII-XIX
}

\author{
Mariano BARRIENDOS \\ Universidad de Barcelona
}

\begin{abstract}
Resumen
La climatología histórica es una especialidad que empieza a tener en Europa un nutrido colectivo de investigadores. El interés por mejorar el conocimiento de la variabilidad climática ha llevado a recuperar información de los archivos históricos para caracterizar el clima del pasado. Los métodos empleados son multidisciplinarios, con una base historiográfica, y una componente cuantitativa para tratar y analizar la información obtenida. Los resultados pueden ser también útiles para la intepretación histórica. Para ilustrar estos aspectos se presenta en este trabajo el caso de Catalunya entre los siglos XViII y XIX.

Palabras clave: Climatología histórica, Fuentes documentales, Miniglaciación, Oscilación Maldá, Riesgos climáticos, Rogativas, Variabilidad climática.
\end{abstract}

\begin{abstract}
Summary
Historical Climatology is an emergent speciality with increasing number of researchers over Europe. Interest to improve knowledge about climatic variability carries on collecting information from historical archives in order to characterize past climate. Methods applied are multidisciplinar. Starting from a historiographical basis for documentary sources and treatment of information, quantitative methods are also applied for data analysis. Results can be useful not only for climatic reconstruction but also for historical explanation. To exemplify these aspects, present work shows results for the case of Catalonia between 18 th and 19 th centuries.

Key Words: Climatic Hazards, Climatic Variability, Documentary Sources, Historical Climatology, Little Ice Age, Maldá Oscillation, Rogation Ceremonies.
\end{abstract}




\section{INTRODUCCIÓN}

La climatología histórica es una especialidad con una trayectoria relevante en Europa Occidental. Los patrimonios documentales de diferente naturaleza están siendo explorados desde el punto de vista climático, encontrando abundante información aunque diseminada en fuentes de diferente titularidad, estructura y contenido. Convertir esa información en datos climáticos objetivos y analizables no es fácil pero es una línea de investigación a desarrollar, en un entorno plenamente interdisciplinario, y con un alto grado de aplicabilidad.

Existen referentes en diferentes países europeos ejemplos ya consolidados sobre este tipo de investigación, desarrollada desde 1980. Quizás es innecesario subrayar el gran potencial que el patrimonio documental español tiene para este tipo de investigación. Por el momento, un número reducido de investigadores ha emprendido labores sistemáticas de recopilación y análisis de información. Cabe destacar, entre otros, el desarrollo de dos tesis doctorales sobre el clima a escala plurisecular, una en Catalunya ${ }^{1}$ y otra en Andalucía Oriental ${ }^{2}$. El esfuerzo interdisciplinario requerido hace que la climatología histórica sea un campo de trabajo abierto a las aportaciones de diferentes colectivos de investigadores. Cualquier esfuerzo individual y aislado está abocado a integrarse o correlacionarse con otros esfuerzos investigadores similares para obtener unos resultados óptimos. La extensión y duración de los fenómenos climáticos, con ámbitos de trabajo pluriseculares e internacionales, hacen evidente esta necesidad.

La labor a realizar es todavía ingente y por su propio carácter interdisciplinario carece de unos ámbitos propios en los que poder aglutinar el personal y los recursos necesarios. El factor positivo que estimula la continuación de la investigación es la utilidad de los resultados. La caracterización de la variabilidad climática y la definición de sus comportamientos extremos tienen dos vías de aplicación. Por un lado, la modelización climática se nutre de los datos recuperados. Su objetivo es la mejora del conocimiento de las manifestaciones del clima y su variabilidad futura, en un escenario de cambio climático inducido por el hombre. Se pone especial énfasis, porque así lo apuntan los resultados de los propios modelos climáticos, en los comportamientos extremos generadores de impactos climáticos de consecuencias catastróficas.

La segunda vía de aplicación, cuya promoción es objetivo de este artículo, sería la introducción de la dinámica climática y sus manifestaciones extremas en la explicación histórica. Se trata de un reto historiográfico difícil, después de las experiencias deterministas de principios del siglo XX. Pero los avances científicos y tecnológicos del siglo XX han potenciado tanto los conocimientos climáticos que sería imposible en la actualidad excederse en la valoración de los fenómenos meteorológicos y climáticos y

1. BARRIENDOS, M.: El clima histórico de Catalunya. Aproximación a sus caracteristicas generales (ss. XV$X I X)$, Tesis Doctoral inédita, Departamento de Geografía Física, Universidad de Barcelona, 1994, 500 p.

2. Rodrigo, F. S.: Cambio climático natural. La Pequeña Edad del Hielo en Andalucía. Reconstrucción del clima histórico a partir de fuentes documentales, Departamento de Física Aplicada, Universidad de Granada. Tesis doctoral inédita, 1994. 
sus repercusiones. Desde la vertiente opuesta, el clima tampoco se puede relegar a un segundo término considerándolo un escenario fijo que no requiere mayor atención en el análisis histórico.

Respecto a los riesgos climáticos, la componente extrema de la variabilidad climática, tienen una especial trascendencia ya que constituyen un fenómeno complejo: en su definición intervienen tanto los fenómenos atmosféricos como factores humanos, lo que los convierte en el punto de encuentro o interacción entre el medio ambiente y el hombre. Las manifestaciones extremas del clima constituyen peligros para el hombre, ante los que la sociedad humana está más o menos expuesta según su nivel de actividades en el medio. La vulnerabilidad resultante es una opción social que se puede disminuir, suprimir pero también agravar según los recursos tecnológicos disponibles y la bondad de las estrategias de mitigación o planificación desarrolladas. El producto final de la interacción de los factores naturales y humanos es el nivel de severidad de los impactos que los riesgos climáticos pueden alcanzar en un colectivo humano determinado, así como su frecuencia temporal y capacidad de afectación en el territorio.

En el presente artículo se plantea como objetivo básico la exposición sintética de los procedimientos de trabajo en climatología histórica, actividad hasta ahora circunscrita al ámbito de la climatología pero que puede resultar de interés en el ámbito historiográfico. Para ello, se detallarán los métodos empleados y se incidirá en la obtención de unos resultados iniciales con la descripción de las características generales del clima en Catalunya entre los siglos XVIII y XIX. Un objetivo final que se pretende desarrollar también es dar pie a la reflexión sobre el encaje que la información generada desde la climatología histórica puede tener entre el colectivo de profesionales de la investigación histórica.

\section{FUENTES Y MÉTODOS EN CLIMATOLOGÍA HISTÓRICA}

\subsection{Fuentes documentales históricas y sus criterios de selección}

La climatología histórica afronta la reconstrucción climática desde fuentes documentales históricas. En este aspecto, es una especialidad regida por criterios historiográficos, pero focalizada en la identificación, recopilación y análisis de informaciones de carácter ambiental que se refieren directa o indirectamente a procesos atmosféri$\cos$.

La idea básica de partida es que cualquier documento del pasado puede contener alguna información de carácter climático. Esta gran disponibilidad es aparentemente favorable, pero es una fuente de problemas porque la cantidad de documentación potencialmente útil siempre excede cualquier plan de trabajo que se pretenda concluir dentro de la «vida útil» de un investigador. Se impone el establecimiento de unos criterios de selección previos, a partir de los cuales una parte del Patrimonio Documental ya no es considerado en la investigación, aún sabiendo que puede contener esporádicamente información útil. 
Los criterios que habitualmente se aplican proceden de autores relativamente recientes ${ }^{3}$ que iniciaron la investigación en climatología histórica en fuentes documentales originales y tuvieron que desarrollar sus propios métodos.

Los criterios de Pierre Alexandre ponen el énfasis en la calidad de los documentos, centrando la selección de los mismos en la fiabilidad del propio documento así como en la credibilidad de la información que contiene. En consecuencia, la investigación en climatología histórica debe centrarse en documentos originales y que contengan descripciones de fenómenos experimentados por la persona que genera el documento o que por lo menos sea contemporánea de los mismos y pueda tener noticia veraz de ellos. Respecto a la información obtenible, Emmanuel Le Roy Ladurie establece unas condiciones mínimas para que su recopilación sea científicamente satisfactoria: debe tratarse de información perfectamente datable, información mínimamente cuantificable, generada y conservada de forma continua en el tiempo y con unos criterios de generación homogéneos a lo largo del tiempo.

Bajo estos criterios, el abanico de fuentes documentales de interés potencial en climatología histórica se reduce a:

- Fuentes de carácter administrativo, por su fiabilidad y continuidad en el tiempo.

- Fuentes agrarias: libros de contabilidad y fiscalidad de explotaciones agrarias.

- Libros de memorias, dietarios, crónicas.

Este tipo de fuentes documentales tienen como características principales su grado de fiabilidad, continuidad en el tiempo y cercanía a la vida cotidiana, donde mejor pueden percibirse los problemas ocasionados por la variabilidad climática y la ocurrencia de fenómenos meteorológicos extremos. Por otra parte, la aparente limitación tipológica no representa una reducción en la riqueza de información a recuperar, pues estas fuentes se encuentran en diferentes segmentos de la sociedad de Antiguo Régimen: Iglesia, autoridades locales, nobleza, agricultores y profesionales de ámbitos urbanos.

$\mathrm{La}$ información a obtener es de dos tipos muy diferenciados. Por un lado, pueden recuperarse descripciones directas de fenómenos meteorológicos o condiciones climáticas generales. Por otro lado, pueden recopilarse informaciones indirectas, también conocidas como proxy-data. Su origen y características formales pueden ser muy dispares, pero todas contienen la repercusión de alguna circunstancia climática desfavorable. Su variedad hace dificil el estabecimiento de una tipología cerrada. Los ejemplos más evidentes serían los registros variables en la producción agrícola o las recaudaciones tributarias asociadas, y los registros de ceremonias de rogativas por motivaciones climáticas.

La experiencia propia en el caso de Catalunya ${ }^{4}$, centrada en ámbitos urbanos, muestra una distribución de la información obtenible en alrededor de un $20 \%$ de des-

3. AleXANDrE, P.: Le climat en Europe au moyen âge, Ecole des Hautes Etudes en Sciences Sociales, Paris. 1987.

LE ROY LADUR1E, E.: Histoire du climat depuis l'an mil, Flammarion, París, 1967.

4. BARRIEndos, 1994, op. cit. BARRIEndos, M.: «El clima histórico de catalunya (siglos XIV-XIX). fuentes, métodos y primeros resultados", Revista de Geografía, 30-31, 1996-1997, pp. 69-96. 
cripciones directas y alrededor del $80 \%$ de proxy-data, en concreto registros sistemáti$\cos$ de ceremonias de rogativas. La abundancia, fiabilidad y variedad de las ceremonias de rogativas las convierten en un fondo de información relevante para la investigación climática $^{5}$. Las ceremonias de rogativas han llegado a convertirse en un proxy-data singular, de origen cultural, asimilable o compatible con otras fuentes proxy de carácter fisico, biológico o humano ${ }^{6}$.

\subsection{Observaciones instrumentales antiguas}

Una fuente de información poco conocida y en consecuencia todavía escasamente explotada en climatología histórica se encuentra en las observaciones meteorológicas instrumentales realizadas antes de la existencia de servicios meteorológicos oficiales. Es una información intrínsecamente correcta y útil, pero su búsqueda y recuperación es dificil por encontrarse en manuscritos originales dispersos según la naturaleza de los observadores que realizaban las mediciones: astrónomos, médicos, religiosos, eruditos naturalistas, aficionados, etc.

El valor de las series recuperadas, además del interes histórico específico por ser reflejo de destacados personajes de la Ilustración, se centra en la capacidad de conectar y solapar las series de datos de carácter proxy con los datos numéricos actuales generados por los servicios meteorológicos públicos. Su número es limitado pero todavía pueden recuperarse series no conocidas a medida que se profundice la investigación. Se trata de un ámbito de trabajo abierto, que contempla los siglos XVIII y XIX en Europa Occidental y la costa Este de Estados Unidos y que ha sido investigado específicamente en proyectos europeos como ADVICE, IMPROVE o EMULATE.

\subsection{Métodos de generación de datos}

La metodología requerida para recuperar y tratar la información y transformarla en series de datos asimilables para la climatología moderna es el aspecto clave de la climatología histórica. Sólo un esfuerzo interdisciplinario real puede aglutinar las pautas historiográficas, con las técnicas estadísticas de tratamiento de series numéricas y el análisis de la variabilidad climática. El objetivo final va dirigido a sintetizar la información y darle una expresión numérica para llegar a series continuas de datos. De ese modo el comportamiento climático en época histórica puede ensamblarse sin excesivos problemas con las variaciones climáticas registradas a partir de observaciones meteorológicas instrumentales.

Para ello se toman aspectos de historia, geografia, estadística, climatología y meteorología con una perspectiva auténticamente interdisciplinaria, de modo que en las especialidades respectivas apenas se dispone de referentes. Se trata, en consecuen-

5. MARTIN VIDE, J. y BARRIENDOS, M.: "The use of rogation ceremony records in climatic reconstruction: a case study from Catalonia (Spain)», Climatic Change, 30, 1995, pp. 201-221.

6. PFISTER, C: Wetrernachhersage; 500 Jahre Klimavariationen und Naturkatastrophen, Verlag Paul Haupt, Bern, 1999. 
cia, de establecer un puente que una vez consolidado permite la aplicabilidad de los resultados en los dos sentidos: permitir análisis climáticos a escalas pluriseculares pero también permitir que la interpretación histórica contemple los fenómenos climáticos con absoluta normalidad.

De forma resumida, el procedimiento de trabajo sigue las siguientes pautas (figura 1): aplicación de sucesivos filtros o criterios de selección para determinar los fondos documentales a consultar en un ámbito espacial y temporal previamente definidos. La consulta sistemática de la documentación seleccionada se realiza filtrando únicamente la información que cumple los criterios preestablecidos. El conjunto final de información se trata generando índices concluyendo así su cuantificación en series de datos, listos para su interpretación según los objetivos específicos de cada investigación.

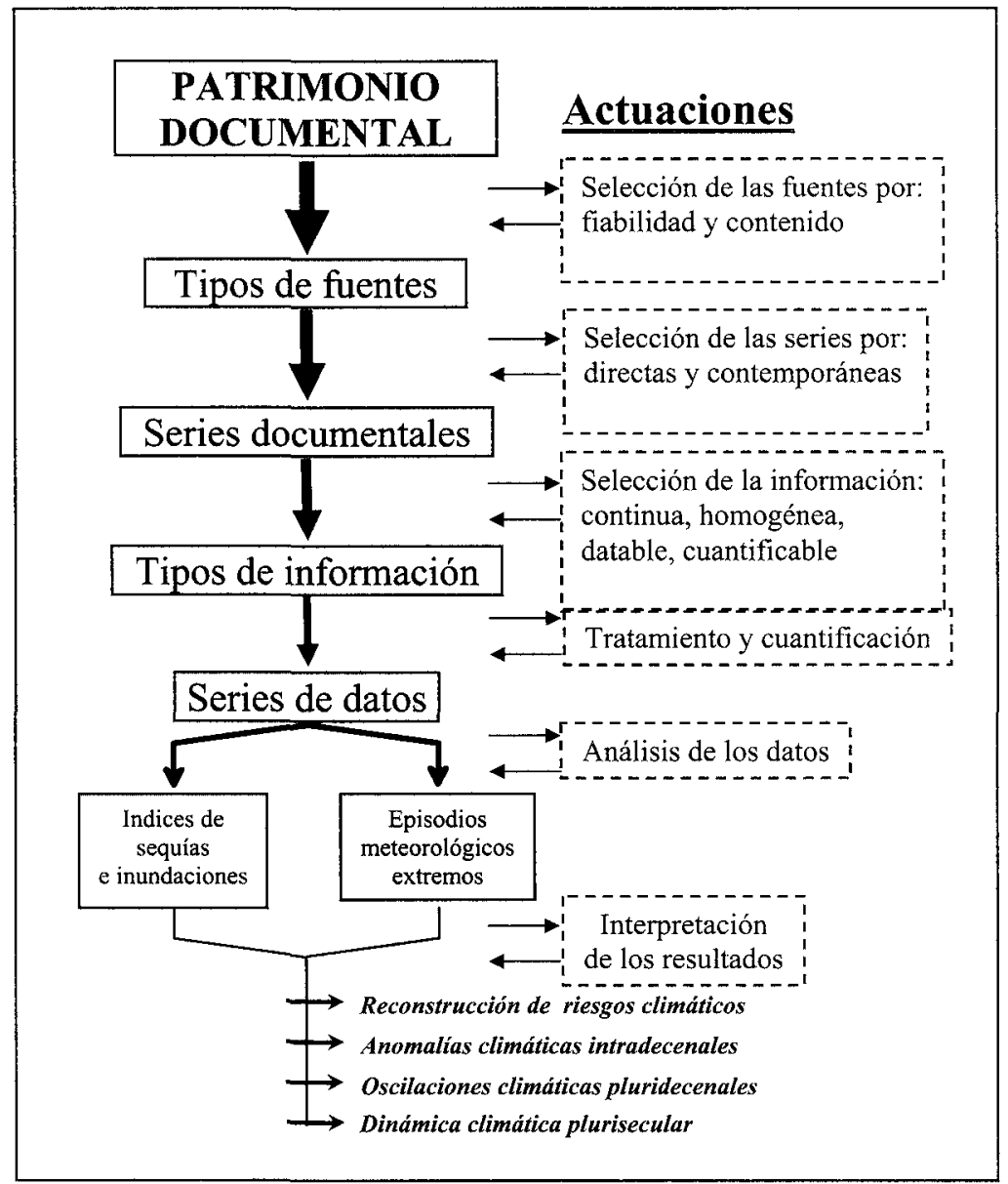

Figura 1. Pautas metodológicas seguidas en climatología histórica (Barriendos, 1994, modificado). 


\section{RESULTADOS Y ESTADO ACTUAL DE LA INVESTIGACIÓN}

\subsection{Información y datos obtenibles}

El clima mediterráneo, que caracteriza de modo más o menos evidente la Península Ibérica, es peculiar por su fuerte variabilidad o irregularidad pluviométrica. En consecuencia, tanto en lo relativo a la reconstrucción del clima del pasado como en la modelización del cambio climático futuro, el tema de mayor interés por su impacto en los recursos hídricos y en el desarrollo socio-económico de las comunidades humanas objeto de estudio son las variaciones experimentadas por la precipitación a diferentes escalas espacio-temporales.

En época histórica, las fuentes documentales que han demostrado un mejor rendimiento para la conservación de información directa asociada a la precipitación son de dos tipos. Por un lado, los libros de memorias y dietarios por las descripciones directas que contienen. Por otro lado, las fuentes administrativas de autoridades locales, civiles y eclesiásticas, tanto por contener esas mismas descripciones directas como por contener el registro sistemático de rogativas pro pluvia y pro serenitate con que los colectivos humanos intentaban hacer frente a las anomalías en la precipitación.

El mecanismo de las ceremonias de rogativas, gracias a su fiabilidad, rigidez formal e implicación de múltiples instituciones, ha devenido en una fuente de información muy útil en la reconstrucción climática. La elaboración de índices hídricos a diferentes resoluciones temporales se ha visto facilitada por la disponibilidad de este tipo de información. La extensión del trabajo a diferentes localizaciones, en cambio, debido al esfuerzo de consulta y recopilación que requiere, es bastante lento y vinculado a la financiación que paulatinamente puede obtenerse?

Por otra parte, la descripción directa de episodios meteorológicos extremos, además de su estudio climático a partir de las cronologías de eventos, permite una mejora en la evaluación actual de los riesgos e impactos climáticos ${ }^{8}$.

En conjunto, lo que se obtiene es una caracterización de la dinámica climática en unas escalas temporales que el empleo exclusivo de observaciones meteorológicas instrumentales no permite.

7. BARRIENdos y MARTín VIDE, 1995, op. cit. BARRIENDOS, M.: «Climatic variations in the lberian Peninsula during the late Maunder Minimum (AD 1675-1715): an analysis of data from rogation ceremonies», The Holocene, 7, 1, 1997, pp. 105-111. BARRIENDOS, M. y LlASAT, M. C.: «The Case of the 'Malda' Anomaly in the Western Mediterranean Basin (AD 1760-1800): An Example of a Strong Climatic Variability», Climatic Change, 61, 2003, pp. 191-216.

8. BARRiendos, M. y MARTin VIDE, J.: «Secular Climatic Oscillations as Indicated by Catastrophic Floods in the Spanish Mediterranean Coastal Area (14th-19th Centuries)», Climatic Change, 38, 1998, pp. 473491.

BARRIENDOS, M.: «Los riesgos climáticos a través de la historia: avances en el estudio de episodios atmosféricos extraordinarios》, en AYALA-CARCEDO, F. J. y OLCINA, J.: Riesgos naturales, Ariel, Barcelona, 2002 , cap. 31, pp. 549-562. 


\subsection{Estado actual de la investigación}

El potencial de desarrollo de esta línea de investigación es ingente, gracias al Patrimonio Documental preservado en numerosas poblaciones, en ayuntamientos o instituciones religiosas. Cientos de kilómetros de estantería están todavía inexplorados en los archivos históricos, por lo que es evidente que el potencial futuro de la climatología histórica en España es inagotable.

Hasta el presente, pueden diferenciarse dos etapas. La primera, desarrollada entre mediados del siglo XIX y mediados del siglo XX, está caracterizada primero por un afán estrictamente recopilatorio, pero con importantes limitaciones en cuanto al acceso a los documentos originales y su análisis metódico y crítico. Durante la primera mitad del siglo XX el uso sesgado de la información obtenida hacia planteamientos deterministas no favorecería en absoluto los primeros esfuerzos recopilatorios. Destacaron en la recopilación de información autores como Manuel Rico Sinobas ${ }^{9}$ y Horacio Bentabol ${ }^{10}$ en el siglo XIX, e Inocencio Font Tullot ${ }^{11}$ y José María Fontana Tarrats ${ }^{12}$ en el siglo XX.

La segunda etapa se desarrolla en el ámbito universitario a lo largo de los últimos decenios del siglo XX y sigue todavía vigente. Después de unos primeros trabajos exploratorios (entre otros, Albentosa ${ }^{13}$, Alvarez ${ }^{14}$, Alberola ${ }^{15}$ ), se han defendido dos tesis doctorales sobre la especialidad ${ }^{16}$ y se ha dado un número creciente de proyectos de investigación que han implicado profesores e investigadores, entre otras, de las

9. RICO SINOBAS, M.: Memoria sobre las causas meteorologico fisicas que producen las constantes sequias de Mucia y Almeria, señalando los medios de atenuar sus efectos, D.S. Compagni, Madrid, 1851.

10. Bentabol, H.: Las aguas de España y Portugal, Vda. e Hijos de M. Tello, Madrid, 2." ed., 1900.

11. Font Tul.tot, I.: Historia del clima de España. Cambios climáticos y sus causas, Instituto Nacional de Meteorología, Madrid, 1988.

12. Fontana Tarrats, J. M.: Entre el cardo y la rosa. Historia del clima en las Mesetas, Madrid, 1971 1977, 269 pp. Obra inédita, mecanografiada.

Fontana TARRATS, J. M.: Historia del clima en Cataluña. Noticias antiguas, medievales y en especial de los siglos XV, XVI y XVII, Madrid, 1976, 248 pp. Obra inédita, mecanografiada.

Fontana Tarrats, J. M.: Historia del clima del Finis Terrae gallego, Madrid, 1977, 127 pp. Obra inédita, mecanografiada.

Fontana TARRATs, J. M.: Historia del clima en el litoral mediterráneo: Reino de Valencia mas Provincia de Murcia, Javea, 1978, 206 pp. Obra inédita, mecanografiada.

Fontana Tarrats, J. M.; Miró-Granada, J. y Vidal, J. J.: El clima de Baleares, hoy y aye: 1450 1700, Madrid, 1974-1975, 104 pp. Obra inédita, mecanografiada.

13. AlbentosA, L. M.: «La importancia del conocimiento de las fluctuaciones climáticas en los estudios históricos. Aproximación al clima de Tarragona durante el siglo XVII», Universitas Tarraconensis, Tarragona, 4, 1981-1982, pp. 73-90.

14. Alvarez, J. A.: «Drought and rainy periods in the province of Zamora in the 17th, 18th, and 19th centuries», in López Vera (Dir.): Quaternayy climate in western Mediterranean. Madrid, Universidad Autónoma de Madrid, 1986, pp. 221-235.

15. AlBEROLA, A.: «La percepción de la catástrofe: sequía e inundaciones en tierras valencianas durante la primera mitad del siglo XVIIn, Revista de Historia Moderna, 15, 1996, pp. 257-269.

16. BARRIENDOS, 1994, op. cit.

RODRIGO, 1994, op. cit. 
Universidades de Alicante, Almería, Barcelona, Granada, Complutense de Madrid y Zaragoza.

El trabajo se ha centrado casi exclusivamente en ámbitos urbanos y documentación privada y administrativa. De todos modos, se están planteando ya trabajos que recuperarían la línea de investigación agraria y fiscal ${ }^{17}$, ya apuntada precozmente por el historiador Emili Giralt Raventós ${ }^{18}$.

La perspectiva de futuro, en consecuencia, es optimista aunque también deja en evidencia un importante retraso temporal respecto al desarrollo experimentado en diferentes paises europeos. Sería muy extensa la relación de trabajos e iniciativas desarrolladas en diferentes países. Baste citar como ejemplo los trabajos de síntesis efectuados para el siglo XVI ${ }^{19}$. La mejor prueba del nivel alcanzado es la creación de bases de datos para su uso en sucesivas investigaciones, en la cual los países centroeuropeos están a la vanguardia con EURO-CLIMHIST (Prof. Christian Pfister, Universidad de Berna, Suiza) y HISKLID (Prof. Rüdiger Glaser, Universidad de Heidelberg, Alemania).

\section{APLICACIÓN PRÁCTICA: EL CLIMA DE LOS SIGLOS XVIII-XIX EN CATALUNYA}

\subsection{Variabilidad climática general}

El clima en Europa desde la Edad Media ha seguido unos patrones de variabilidad caracterizados por dos grandes episodios climáticos, de unos cinco siglos de duración cada uno. El primero, conocido como episodio cálido medieval, tuvo lugar aproximadamente entre los siglos VIIl y XIV. Se sabe poco de él, salvo la bonanza de las temperaturas (entre uno y dos grados más en la temperatura media anual), superiores en términos medios a las del siglo XX, incluso contando ya el calentamiento global inducido por el hombre. De las precipitaciones se puede deducir, con el nivel de información disponible en la actualidad, que eran similares a las actuales pero mejor distribuídas a lo largo del año y más regulares interanualmente.

17. Garcia Herrera, R.; Macías, A.; Gallego, D.; Hernández, E; Gimeno, L. y Ribera, P: "Reconstruction of the precipitation in the Canary Islands for the period 1595-1836\%, Bulletin of the American Meteorological Society, 81, 1037-1039, 2003, pp. 68-77.

18. GIRALT, E.: «En torno al precio del trigo en Barcelona durante el siglo XVI», Hispania, 70-73, 18, Madrid, 1958, pp. 38-61.

19. Brazdil, R.; Glaser, R.; Pfister, C.; Antoine, J. M.; Barriendos, M.; Camuffo, D.; Deutsch, M.; EnZi, S.; GUidoboni, E.; Rodrigo, F. S.: «Flood events of selected rivers of Europe in the Sixteenth Century», Climatic Change, 43, 1999, pp. 239-285.

Glaser, R.; Brazdil, R.; Pfister, C.; Dobrovolny, P; Barriendos, M; Bokwa, A.; Camulfo, D.; Kotyza, O.; Limanowka, D.; RaCz, L.; Rodrigo, F. S.: «Seasonal Temperature and Precipitation fuctuations in Selected parts of Europe during the Sixteenth Century», Climatic Change, 43, 1999, pp. $169-200$.

Pfister, C.; Brazdil, R.; Glaser, R.; Barriendos, M.; Camuffo, D.; Deutsch, M.; Dobrovolny, P.; Enzl, S.; Guidoboni, E.; Kotyza, O.; Milmzer, S.; RACZ, L.; Rodrigo, F. S.: «Documentary evidence on Climate in Sixteenth Century Europes, Climatic Change, 43, 1999, pp. 55-110. 
Entre los siglos XIV y XIX tuvo lugar un episodio climático de características opuestas al anterior. La conocida como miniglaciación, tras un deterioro progresivo del clima a lo largo del siglo XIV, supuso una etapa de clima adverso con temperaturas inferiores a las actuales (entre uno y dos grados menos en la temperatura media anual). Pero el factor más significativo quizás fue la alteración del régimen pluviométrico: sin un importante cambio en los valores medios de precipitación, su distribución se hizo mucho más irregular que en siglos anteriores o que en la actualidad. Lo más visible de este periodo es la sucesión de eventos severos de sequía o de lluvias persistentes, en ambos casos de fuerte impacto en la agricultura, y el incremento en la frecuencia de aparición de hidrometeoros catastróficos de gran magnitud: inundaciones por lluvias torrenciales, grandes nevadas, temporales de mar, etc. Los trabajos de síntesis realizados con información procedente de diferentes especialidades paleoclimáticas no deja lugar a dudas de la severidad de este episodio ${ }^{20}$.

La variabilidad detectada en Catalunya demuestra que internamente la miniglaciación tampoco se manifestaba con unas condiciones estables. Una sucesión de picos en la frecuencia de fenómenos extremos, conocidos como oscilaciones climáticas ${ }^{21}$, se distribuyen entre el siglo XVI y el siglo XIX, separados por periodos temporales de relativa normalidad. Este comportamiento temporal (Figura 2) tiene como elementos destacados dos oscilaciones muy acusadas con un incremento de los hidrometeoros catastróficos (inundaciones, nevadas, temporales de mar, lluvias persistentes) acompañado de un descenso en la aparición de sequías: entre los años 1580-1620 y 1820 1860. Una tercera oscilación, de características peculiares pues supone un incremento en la frecuencia de los hidrometeoros catastróficos pero también de las sequías, se produce entre 1760 y 1800 y recientemente ha sido bautizada como Oscilación Maldá en honor al barón de Maldá que sufrió estas inclemencias climáticas y las documentó prolijamente ${ }^{22}$.

A la vista de estas características generales, el periodo que comprendió la Oscilación Maldá y los decenios siguientes hasta mediados del siglo XIX no fueron nada fáciles para las actividades humanas, por lo menos en la cuenca del Mediterráneo Occidental. La investigación climática ha identificado diferentes procesos meteorológicos (generados por la circulación general atmosférica) que explicarían las anomalías detectadas, pero falta por conocer el conjunto de factores o causas que expliquen ese comportamiento anómalo de la atmósfera. Por el momento, lo que puede establecerse es la secuencia de eventos que caracterizan el periodo. Para el caso de Catalunya, esta sucesión de fenómenos meteorológicos extremos es la más acusada de los últimos 500

20. Grove, J. M.: The Little Ice Age, Routledge, Londres, 1988.

BRADLEY, R.S. y Jones, P. D. (dirs.): Climate Since A.D. 1500, Routledge, L̇ondres, 1992.

Luterbacher, J.; Xoplaki, E. ; Dietrich, D.; Rickli, R. ; Jacobeit, J.; Beck, C.; Gyalistras, D.; SCHMUTZ, C.; WANNER, H.: «Reconstruction of sea level pressure fields over the Eastern North Atlantic and Europe back to 1500», Climate Dynamics, 18, 2002, pp. 545-561.

21. BARRIENDOS, 1994, op. cit.

22. BARRIENDOS y LLASAT, 2003, op. cit. 


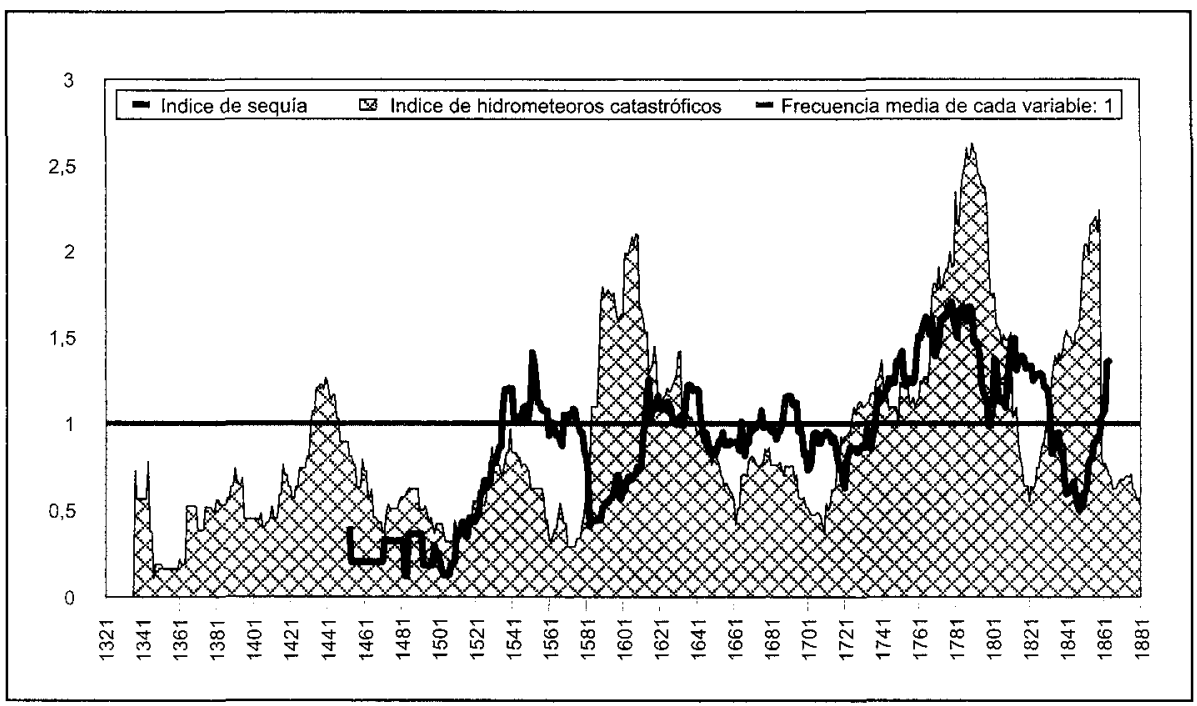

Figura 2. Frecuencia de los índices de sequía e hidrometeoros catastróficos en Catalunya. Valores expresados en medias móviles de 31 años (Barriendos, 1996-1997)

años y probablemente de los últimos 1000 años. Y no sólo por la magnitud singular de alguno de los eventos, sino especialmente por su frecuencia, variedad y rápida sucesión.

\subsection{El comportamiento de la precipitación: inundaciones y sequías}

Desarrollar en el presente trabajo una crónica pormenorizada de todos los episodios meteorológicos extremos sería muy extenso y repetitivo. Mostrando dos de los casos singulares podrá quizás apreciarse mejor la severidad de los fenómenos y cómo debió sufrir la población la ocurrencia de sucesivos eventos de similar naturaleza y magnitud.

Las inundaciones de octubre de 1787

La orografia alrededor del Mediterráneo tiene relieves importantes y abruptos, lo que explica la presencia de avenidas torrenciales cuando las lluvias se exceden en su intensidad. Las cuencas pequeñas sufren a menudo este tipo de problemas. Lo que ya no es tan habitual es que los ríos principales de grandes cuencas experimenten crecidas muy grandes y prolongadas, ya que tienen mayor capacidad para distribuir las crecidas en el tiempo, evitando concentraciones de caudal excesivamente grandes en un mismo momento. Este es el caso de las lluvias torrenciales de principios de octubre de 1787: fueron capaces de ocasionar unos desbordamientos excepcionales en los ríos Segre y Ebro. El evento fue especialmente grave en Tortosa, donde hasta la actualidad los 


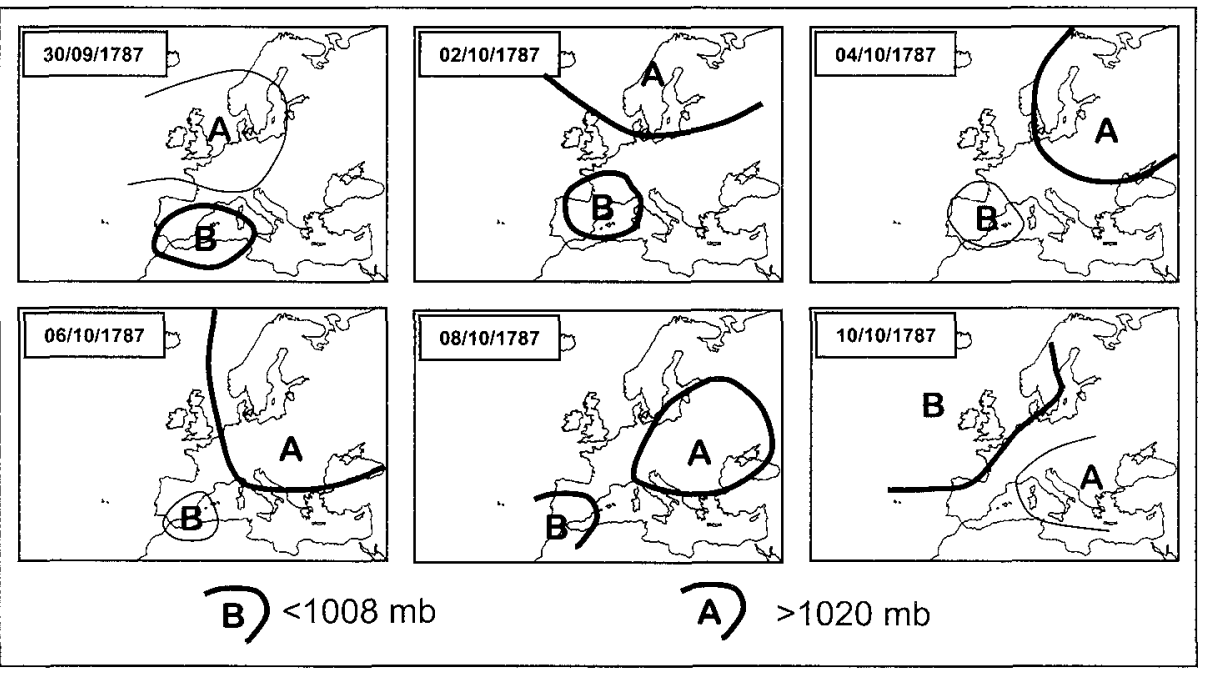

Figura 3. Configuraciones sinópticas diarias durante el evento de inundaciones en la cuenca del Ebro, 8-10 de octubre de 1787 .

niveles de inundación del mismo no han sido superados: $8,73 \mathrm{~m}$. de altura de agua por encima del nivel de estiaje, 183 fallecidos, 518 edificios derruídos dentro de poblaciones y 666 edificios en huertas ${ }^{23}$.

Las observaciones meteorológicas antiguas, generadas por médicos, astrónomos y aficionados, permiten efectuar una aproximación a la situación sinóptica que explica las lluvias persistentes y prolongadas (figura 3). Un anticiclón muy potente instalado en Rusia impedía la circulación habitual de borrascas desde el Atlántico por las latitudes medias-altas de Europa. Una borrasca en concreto quedó retenida sobre la Península Ibérica. La inestabilidad ejercida por esta borrasca, más la llegada de aire húmedo procedente del Mediterráneo impulsado por el anticiclón, como «llevants» (Este) y «xalocs» (Sudeste) muy fuertes ${ }^{24}$, facilitó las precipitaciones torrenciales. Es un mecanismo habitual, pero en esta ocasión su duración sobre una misma región o sistema fluvial fue anómala y el factor clave del impacto catastrófico producido: El día 30 de septiembre ya estaba la borrasca en la mitad oriental de la Península Ibérica y sólo el 10 de octubre se restablece una situación normal y que puede suponer el cese de las precipitaciones. Para ese momento, el sistema fluvial del Ebro estaba registrando unos desbordamientos extraordinarios. Pero las circunstancias atmosféricas fueron adversas

23. FERnÁndez DOMingo, D.: Anales o Historia de Tortosa, desde su fundación hasta nuestros días, Jaime Jepús, Barcelona, 1867.

BRU, F. M.: Fulls d'història de la vila de Tivissa i del seu territori antic, Aymá, S.L., Tarragona, 1955.

24. BRU, 1955, op. cit. 


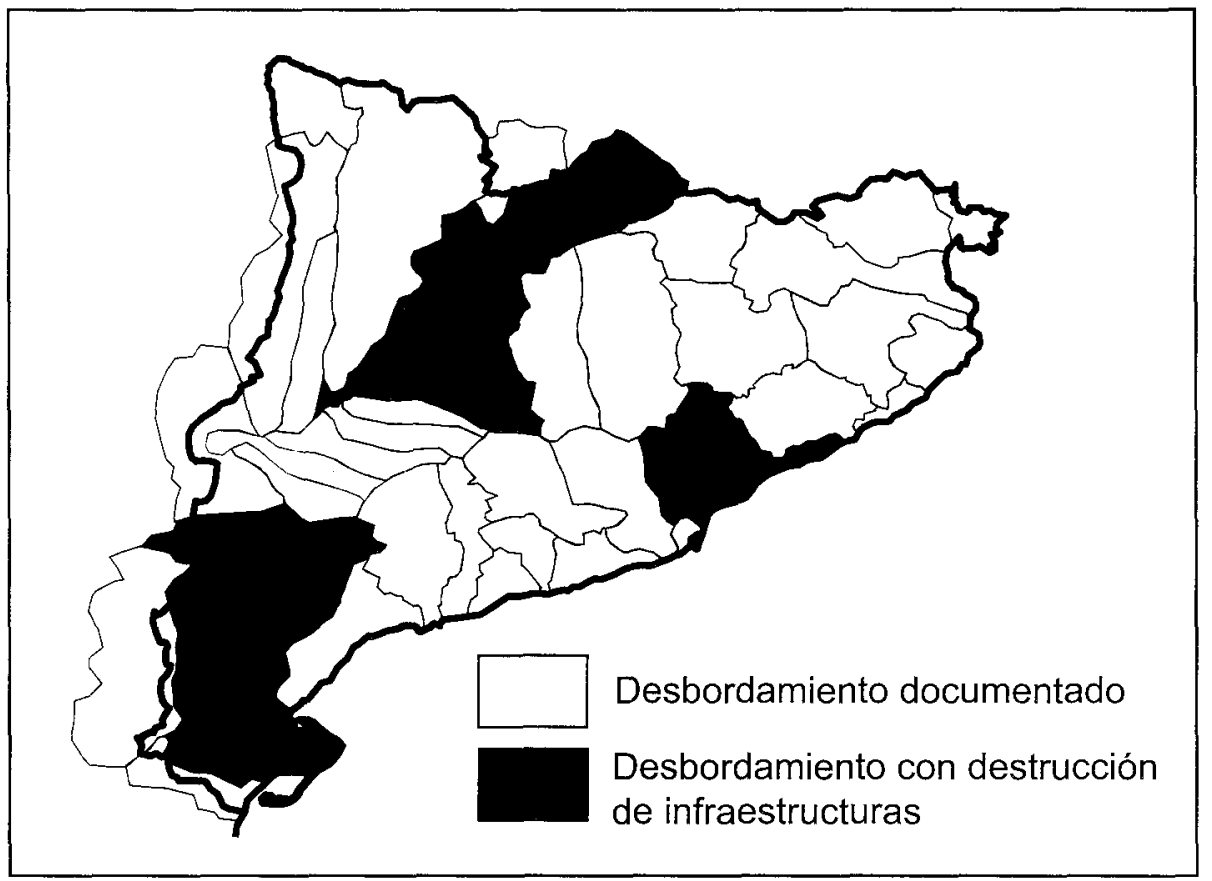

Figura 4. Cuencas fluviales afectadas por el evento de inundación de octubre de 1787 en Catalunya.

para una extensión mucho mayor: Otras cuencas en Catalunya registraron desbordamientos y daños de carácter catastrófico (figura 4), por lo que se pone de manifiesto el impacto en la sociedad que este tipo de eventos, pese a su baja frecuencia, pueden llegar a ocasionar.

\section{La sequía de 1812-1824}

La sequía es uno de los fenómenos característicos del clima mediterráneo, apareciendo con relativa frecuencia y con magnitudes y duraciones muy variadas. Los efectos de déficit pluviométrico son generales e inciden tanto en el medio natural como en el antrópico, y por igual en sociedades pre-industriales o modernas: actividades agrarias y agrícolas, industriales y de producción energética, abastecimiento directo a la población y de forma creciente en los servicios. Hay dos aspectos que la hacen especialmente severa. En primer lugar, sus efectos son acumulativos y crecientes, por lo que una sequía duradera requiere mucho más tiempo para compensar sus efectos, ya sea por la pérdida de cosechas, empobrecimiento del suelo, afectación de la vegetación natural, disminución o pérdida de acuíferos. Por otro lado, las sequías son uno de los riesgos climáticos que presenta una mayor capacidad de afectación sobre el territorio y en el tiempo. Sin duda, y en consecuencia, es uno de los riesgos climáticos que produce 
impactos de mayor severidad, tanto por la afectación del medio natural como por las pérdidas ocasionadas en los sistemas socio-económicos.

El estudio de reconstrucción de sequías ha empezado a dar unos primeros frutos pero sólo en el ámbito de la meteorología y la climatología. Se están caracterizando y definiendo los patrones que en la circulación general atmosférica generan sequías de muy baja frecuencia pero severidad extraordinaria. Lo que resulta mucho más complejo es la valoración de los impactos en el medio físico y el antrópico: la sequía es un fenóme-
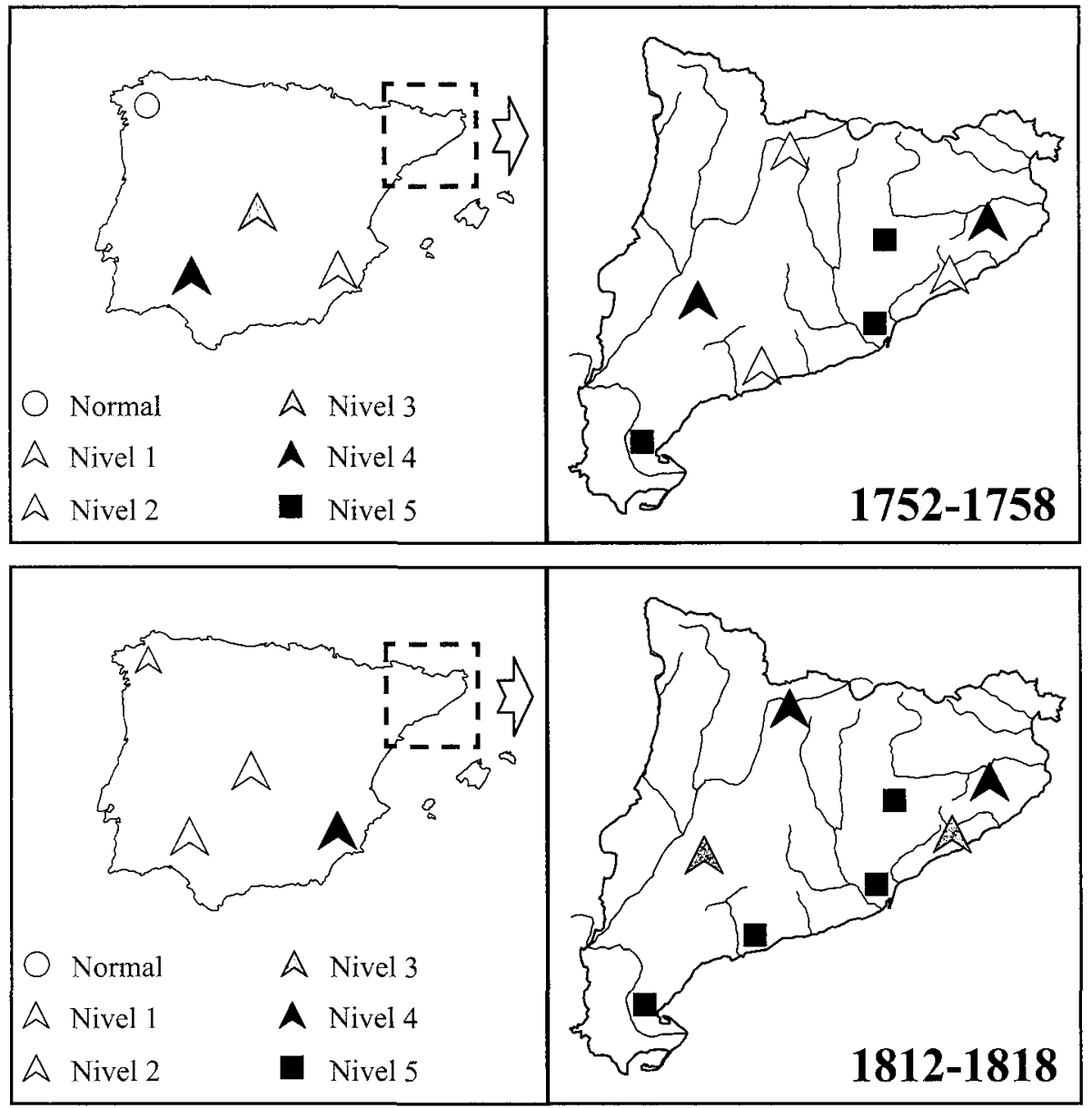

Figura 5. Reflejo de dos eventos de sequía en las rogativas pro pluvia. Adaptado de Barriendos, M. en Lehmann, H. (et al.): «Cuture and Climate in Spain», Kulturelle Konsequenzen der Kleinen Eiszeit, MaxPlanck-Institut für Geschichte (en prensa).

Leyenda:

Normal: ausencia de rogativas. Nivel 1: rogativas simples. Nivel 2: exposición de reliquias. Nivel 3: procesiones públicas. Nivel 4: inmersión de reliquias o ceremonias de solemnidad equiparable. Nivel 5: peregrinaciones a santuarios especializados. 


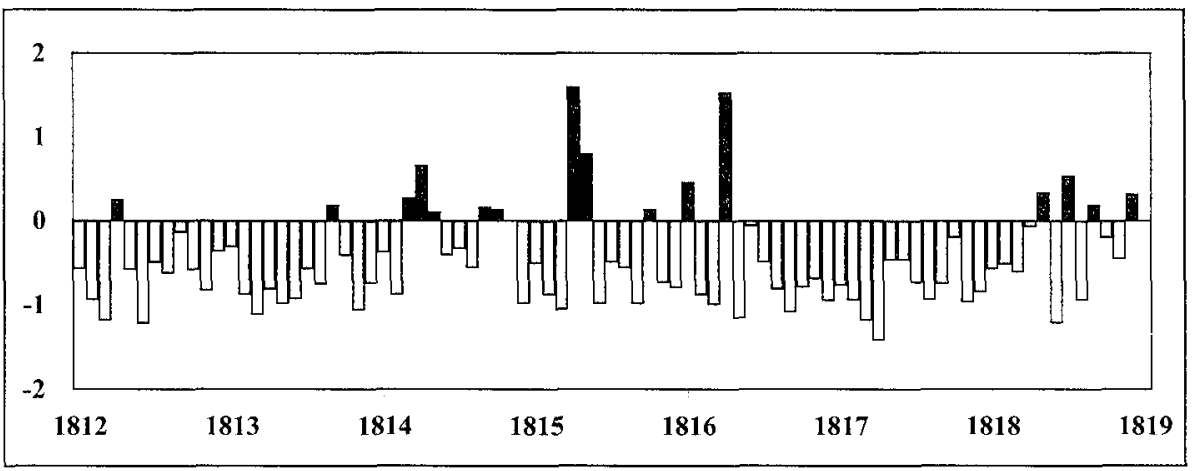

Figura 6. Valores normalizados de precipitación total mensual para Barcelona, 1812-1818. El valor «0» corresponde a la media (Barriendos y Dannecker, 1999).

no silente, es difícil detectar su inicio, sus efectos son progresivos, extensos y dilatados en el tiempo, y las repercusiones indirectas o inducidas son muy variadas y complejas.

El estudio de las sequías todavía es más prolijo que el de las inundaciones, debido a su mayor frecuencia y diversidad de áreas potencialmente afectadas. El periodo sobre el que en el presente trabajo realiza el análisis, tuvo unas sequías en general de magnitud baja pero de acusada frecuencia. Pero en dos ocasiones se registraron sequías muy acusadas y prolongadas. El registro de rogativas pro pluvia recopilado en diferentes localizaciones así lo pone de manifiesto (figura 5): el evento de 1752-1758 hizo que de las ocho poblaciones catalanas de las que se disponen registros continuos, en tres de ellas se alcanzara el nivel máximo de rogativas existente. Durante el evento de 18121818 se llegó a esta situación en cuatro poblaciones.

El segundo evento fue seguido por Francisco Salvá con sus observaciones instrumentales ${ }^{25}$. El déficit en las precipitaciones registradas, a pesar de los posibles problemas generados por el instrumental antiguo o los métodos de trabajo poco ortodoxos, no tiene referentes equiparables en todo el siglo XX. El comportamiento mensual de la precipitación fue de condiciones de sequía casi continua (figura 6): sólo el 19\% de los meses tuvieron una precipitación superior a la normal, pero sólo el 2,4\% fueron meses pronunciadamente lluviosos (valores superiores a la media más una desviación estándar) mientras que el 11,9\% fueron pronunciadamente secos (valores inferiores a la media menos una desviación estándar) ${ }^{26}$. Dentro del episodio de sequía hubo momentos de severidad muy acusada. Por ejemplo, el año 1817 presenta una precipitación total de sólo 196 milímetros, cuando los totales medios en la zona de Barcelona suelen

25. Archivo de la Real Academia de Medicina de Barcelona, Francisco Salvá y Campillo, Tablas Meteorológicas, 3 vols., 1780-1824.

26. BARRIENDOS, M. y DANNECKER, A.: «La sequía de 1812-1824 en la costa central catalana. Consideraciones climáticas e impacto social del evento», en Raso, J. M. y Martín Vide, J. (eds.): La climatología española en los albores del siglo XXI, Oikos-Tau, Barcelona, 1999, pp. 53-62. 


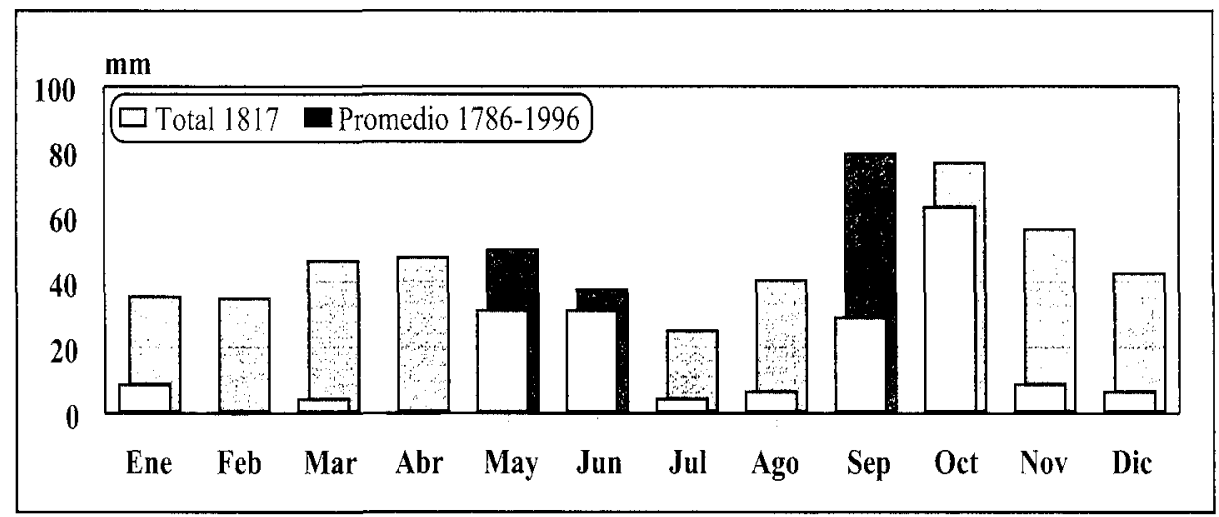

Figura 7. Precipitación total mensual en Barcelona el año 1817 respecto a los valores medios (Barriendos y Dannecker, 1999).

estar alrededor de los 580 milímetros. El comportamiento mensual es además muy perjudicial para las actividades agrarias pues además de la habitual sequía estival, las precipitaciones de primavera son casi nulas y las de otoño muy limitadas. Con esta distribución de las precipitaciones, las cosechas de cereal de secano sufrían tanto en su maduración como en el momento de la siembra (figura 7).

La situación meteorológica que caracterizó la sequía de 1812-1818 no fue en absoluto diferente de las propias de las sequías actuales. Los registros de presión atmosférica de diferentes ciudades europeas de la época permiten identificar la presencia de altas presiones ubicadas entre Centroeuropa y la costa europea occidental, de tal modo que existían serias dificultades para que las borrascas de procedencia atlántica pudieran penetrar hacia el área mediterránea pero a su vez dificultaban la formación de depresiones en la propia cuenca mediterránea. Baste el ejemplo de dos meses habitualmente lluviosos como marzo y noviembre de 1817 (figura 8): marzo de 1817 experimentó un centro de altas presiones en Europa Occidental muy extendido y estático. Sólo se aprecian bajas presiones entre Islandia y el Norte de Escandinavia. Barcelona registró 4,5 milímetros de los 46,4 que son habituales: un solo día de lluvia fruto del paso de una borrasca que dejó una leve granizada. El mes de noviembre del mismo año, el anticiclón no era tan extenso pero seguía ubicado en Europa Occidental, conectado con otro centro de altas presiones en Centroeuropa. Las borrascas circulaban entre Escocia y Escandinavia y las situaciones de inestabilidad en Catalunya tuvieron que ser muy escasas: el registro instrumental sólo muestra 5 días de lluvia en todo el mes, acumulando una precipitación de 9,0 milímetros cuando el promedio de noviembre en Barcelona es de 56,8 milímetros y son frecuentes los valores entre 100 y 200 milímetros. 

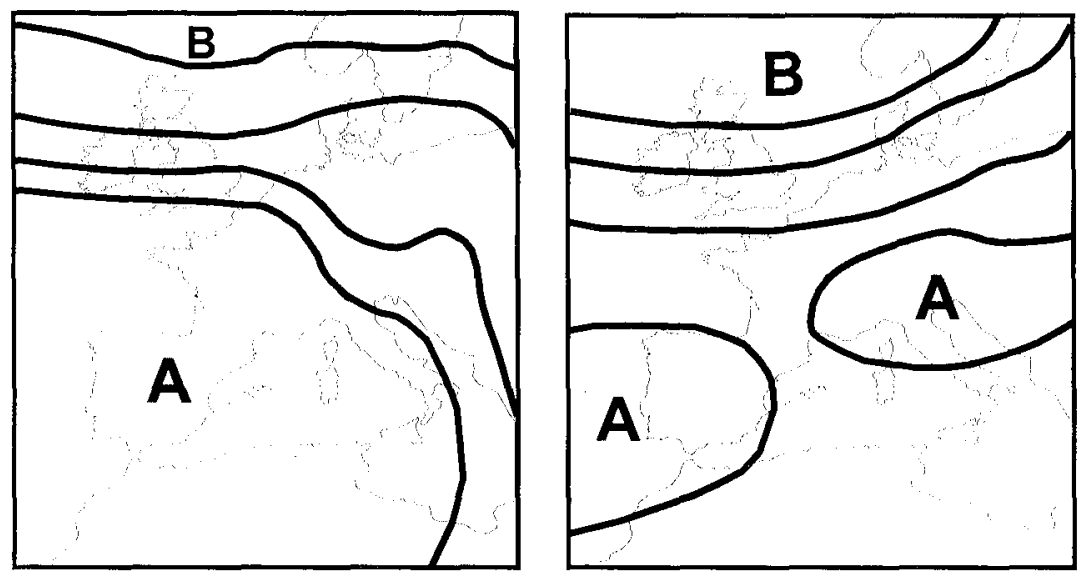

Figura 8. Configuración atmosférica media para el mes de marzo (izquierda) y noviembre (derecha) de 1817. Meses típicamente lluviosos pero con presencia esta vez de anticiclones con estabilidad atmosférica prolongada.

\subsection{El comportamiento de las temperaturas: olas de frío y nevadas}

El régimen térmico tiene un reflejo muy incompleto y discontinuo en la documentación manuscrita. Ello impide disponer de un seguimiento continuo de las variaciones térmicas del mismo modo que se realiza con las pluviométricas.

La información recopilada en Catalunya ${ }^{27}$ permite al menos detectar los momentos en que existe una frecuencia elevada de manifestaciones térmicas anómalas. Su análisis, del mismo modo que ocurrió con las precipitaciones, muestra una concentración desde mediados del siglo XVIII hasta mediados del siglo XIX.

Olas de frío

La presencia de olas de frío durante el periodo es notoria por dos aspectos diferentes. En primer lugar, porque se produce una ola de frío de excepcional duración, desde mediados de diciembre de 1788 hasta mediados de enero de $1789^{28}$. Sus valores térmicos no representaron récords absolutos pese a su dureza. El origen de su excepcionalidad y severidad de impactos fue por la extensión afectada (toda Europa) y la duración

27. BARRIENDOS, 1994, op. cit.

28. Barkiendos, M.; Peña, J. C.; MARtín Vide, J,; Jonsson, P.: «The Winter of 1788-1789 in the Iberian Peninsula from meteorological reading observations and proxy-data records», Actas del Congreso Giuseppe Toaldo e il Suo Tempo (1719-1797). Scienza e Lumi tra Veneto ed Europa, Padova, 2000, pp. 921-942. 
tan prolongada. Sólo como ejemplo, París registró temperaturas negativas continuadas desde finales de noviembre de 1788 hasta mediados de enero de 1789. Cabe suponer la trascendencia de los daños ocasionados en la agricultura ante un déficit térmico tan severo: afectación de las cosechas anuales, pero también muerte de arbustos y árboles frutales. Tampoco es despreciable la afectación experimentada en la actividad artesanal, al quedar los molinos hidráulicos bloqueados durante largo tiempo y en los transportes en Centroeuropa al no poderse navegar por ríos y canales.

En Catalunya no se llegó a valores termométricos extraordinarios: en la desembocadura del Llobregat se registraron hasta $-3,8^{\circ} \mathrm{C}$ y en Barcelona ciudad hubo varios días que se llegó al punto de congelación. Pero otros indicadores son notables: nunca hasta entonces, ni después, la ciudad de Barcelona ha registrado dos nevadas de gran grosor (un palmo o más de grosor según las localizaciones) en un intérvalo de 10 días. Del mismo modo, el río Ebro en Tortosa tampoco había registrado dos heladas completas en el plazo de dos semanas ${ }^{29}$.

Otro episodio singular se debió a la erupción del volcán Tambora. El verano del año siguiente a la erupción, el de 1816, tuvo unas temperaturas extremadamente bajas en toda Europa con nevadas copiosas que dejaron las cosechas y los pastos inaccesibles. La hambruna no tuvo precedentes por su origen tan peculiar, quedando referido como «el año sin verano» ${ }^{30}$.

Las circunstancias especiales, como el déficit en el balance radiativo inducido por el aerosol estratosférico de una erupción volcánica se veía sucedido por eventos climáticos de difícil interpretación, como el periodo 1825-1835 en el que existe una concentración de referencias documentales sobre fríos acusados y extemporáneos en Catalunya.

Un conjunto de datos relevantes para apreciar la severidad del frío registrado en este periodo lo ofrece el municipio de Seu d'Urgell, población a unos 700 metros de altitud, en la confluencia de los ríos Valira y Segre, suficientemente habituada y preparada para el frío como para sólo acusar su impacto en situaciones extraordinarias. Las olas de frío que más impactaban en esta población, por lógica, eran las extemporáneas, aquellas que se producían en otoño y especialmente en primavera, cuando podían afectar gravemente el desarrollo de los cultivos. En plena Oscilación Maldá, el Ayuntamiento convocó rogativas contra el frío, cosa no documentada hasta el momento, ya que se estaban dañando los cultivos. El 20 de abril de 1772 se realizaron rogativas simples a San Armengol y San Odón intra ecclesiam contra el frío excesivo, pero la persistencia del mismo hizo que se realizaran rogativas de mayor entidad el 1 de mayo, dejando las imágenes de ambos santos expuestas sin ropa ni ornamentos. El 28 de mayo se dio por terminado el periodo de crisis celebrándose un Te Deum Laudamus en acción de gracias ${ }^{31}$.

29. Barriendos et al., 2000, op. cit.

30. STOTHERS, R. B.: «The great Tambora eruption in 1815 and its aftermath», Science, 224, 4654, 1984, pp. 1191-1198.

31. Archivo Histórico Municipal de Seu d'Urgell, «Llibre de notes comensat en lo any de $1726 », 1$ vol., 1726-1819.

Archivo Histórico Municipal de Seu d'Urgell, «Llibres de Consells», 1434-1936, 44 vols. 
Un evento de este tipo era un problema para la actividad agraria, pero su ocurrencia solía estar aislada en el tiempo, por lo que la recuperación era asumible. Sin embargo, dentro del periodo estudiado, la propia población registró una secuencia de olas de frío que pudieron representar un impacto mucho más serio debido a su concentración. La documentación municipal conserva un registro denso pero aislado de rogativas contra el frío, de primavera u otoño: 1 de mayo de 1826, 19 de mayo de 1827,23 de abril de 1831,11 de mayo de 1832,6 de septiembre de 1833,28 de abril de 1836 y 16 de enero de 1837. En el último caso, la ola de frío era invernal pero debió presentar tal magnitud que la población pasó apuros muy serios: las rogativas no eran suficientes y tuvo que organizarse una sopa económica para la población humilde ${ }^{32}$.

\section{La aparición de nevadas en Barcelona}

Las nevadas importantes en sectores bajos o cercanos al litoral constituyen un fenómeno poco usual y sintomático de anomalías en la circulación atmosférica. Prescindiendo de los efectos que produce, quizás más vinculados a la escasa práctica o adecuación de las poblaciones que al fenómeno propiamente dicho, existen unos promedios de ocurrencia cuya alteración es también indicativa de anomalías climáticas: en el caso de la ciudad de Barcelona, en el periodo 1935-1970 se produjo en promedio una nevada cada 10 años en el centro urbano que llegara a cuajar. En el periodo objeto de estudio, en concreto entre 1788 y 1844 el promedio de ocurrencia de nevadas de este tipo se reduce a una cada 5 años. En el decenio 1791-1800 se llegó al máximo promedio con 5 nevadas de grosor notable: una nevada cada 2 años. Fueron los eventos de 24 de diciembre de 1788, 7 de enero de 1789, 28 de diciembre de 1794, 19 de febrero de 1795,1 de marzo de 1796, 7 de marzo de 1796, 21 de diciembre de 1799, 14 de marzo de 1813,25 de diciembre de 1829,1 de febrero de 1830 y 4 de diciembre de $1844^{33}$.

\section{REFLEXIONES SOBRE LA CLIMATOLOGÍA HISTÓRICA}

El estudio de las fuentes documentales históricas desde punto el punto de vista climático tuvo una primera etapa de simple identificación y datación de eventos sin otro objetivo que su recopilación en listados sucintos. Desde un punto de vista actual resulta evidente que este material no podía ser más que una etapa inicial de cualquier investigación científica rigurosa. Sin embargo, debe admitirse el error que se produjo a principios del siglo $\mathrm{XX}$ al querer introducir en el discurso histórico una información climática que por si misma no aportaba nada relevante atribuyéndole la capacidad de explicar por por si sola los hechos históricos de cualquier época.

Estos planteamientos deterministas fracasaron y generaron un rechazo hacia la climatología histórica, todavía más vivo en España por lo tardío de algunas manifestaciones deterministas, como las de Ignacio Olagüe o José María Fontana Tarrats.

32. Archivo Histórico Municipal de Seu d'Urgell, «Llibres de consells i resolucions», fechas referidas.

33. BARRIENDOS, 1994, op. cit. 
El clima no debe entenderse como un suplemento al resto de procesos que participan en la explicación histórica, ni en la sociedad moderna ni en sociedades pretecnológicas. La reconstrucción climática de época histórica, además de ser una parte importante de la investigación en variabilidad climática y un apoyo incluso para la modelización climática, puede llegar a ser un complemento para mejorar o dar soporte al análisis histórico. Un complemento que ayuda a entender contextos cambiantes en los que las comunidades humanas desarrollan sus actividades.

La climatología histórica podría ser considerada incluso como una ciencia auxliar de la historia: una herramienta con un lenguaje y unas expresiones numéricas propias que trabaja en una parcela muy específica del pasado para proporcionar al historiador una imagen lo más aproximada posible del contexto ambiental que se experimentaba en el ámbito espacio-temporal en el que se desarrolle una investigación.

Sólo en situaciones espacial y temporalmente muy definidas, el clima puede llegar a ser un elemento de explicación histórica. Por ejemplo, en el ámbito mediterráneo donde los riesgos climáticos son relativamente frecuentes y con un fuerte impacto, esas manifestaciones extremas del clima en momentos puntuales hacen actuar a las autoridades y la población de una manera determinada. Se ponen en tensión los recursos económicos y tecnológicos, las instituciones, y la sociedad genera unas respuestas, que pueden ser simplemente paliativas o llevar incorporada una capacidad preventiva para situaciones similares futuras.

La singularidad de los elementos climáticos, su variabilidad y sus manifestaciones extremas, radica en que para un colectivo humano son un contexto que puede representar tanto un impacto negativo como un recurso o factor positivo; y eso depende en buena medida del nivel de tolerancia, la actitud de superación y la capacidad de respuesta del colectivo humano. Un ejemplo típico sería el de una batalla entre dos contendientes, sometidos al mismo escenario meteorológico: en la batalla de Trafalgar, el último encuentro de grandes navíos de línea a vela de la historia, el viento no fue el protagonista de la batalla ni favoreció que los ingleses ganaran la batalla. El viento era el escenario dado para ambos contendientes. En ese escenario, ese día entablaron combate dos escuadras, y en una de ellas había unos oficiales que supieron aprovechar las circunstancias del escenario en su propio beneficio para vencer al contrario, y haciendo que esa victoria tuviera un valor decisivo en la contienda general que se daba en Europa, de tal modo que uno de sus enemigos teminó siendo un fiel aliado al fỉnal de la guerra. Y todo ello con el almirante en jefe malherido en medio del combate.

Situaciones meteorológicas y climáticas adversas como las del periodo 1780 1840 también muestran que el clima puede crear escenarios o contextos en los que cualquier sociedad debe consumir o perder una parte importante de sus recursos humanos, económicos y tecnológicos para recuperarse de los daños ocasionados, tanto por su magnitud como por su reiteración.

Lo que parece evidente es que el clima no puede estar ausente de la historia ni debe monopolizar su explicación. Debe considerarse su participación en los hechos históricos de un modo objetivo y ajustado a la realidad. Para ello, la climatología histórica debe investigar y generar los datos y herramientas lo más completas posible para 
facilitar su comprensión en un entorno científico interdisciplinario tan interesado por los eventos ya sucedidos como por los eventos que pueden volver a ocurrir en un futuro próximo.

\section{BIBLIOGRAFIA}

AlBentosA, L. M.: «La importancia del conocimiento de las fluctuaciones climáticas en los estudios históricos. Aproximación al clima de Tarragona durante el siglo XVIl»», Universitas Tarraconensis, Tarragona, 4, 1981-1982, pp. 73-90.

AlBerolA, A.: «La percepción de la catástrofe: sequía e inundaciones en tierras valencianas durante la primera mitad del siglo XVIII), Revista de Historia Moderna, 15, 1996, pp. 257-269.

AlEXANDRE, P.: Le climat en Europe au moyen âge, Ecole des Hautes Etudes en Sciences Sociales, París, 1987.

ÁlVAREZ, J. A.: «Drought and rainy periods in the province of Zamora in the $17 \mathrm{th}, 18 \mathrm{th}$, and 19 th centuries), in López Vera (Dir.): Quaternary climate in western Mediterranean. Madrid, Universidad Autónoma de Madrid, 1986, pp. 221-235.

BARRIENDOS, M.: El clima histórico de Catalunya. Aproximación a sus caracteristicas generales (ss. $X V-X Y X)$, Tesis Doctoral inédita, Departamento de Geografia Física, Universidad de Barcelona, 1994, $500 \mathrm{p}$.

- «El clima histórico de Catalunya (siglos XIV-XIX). Fuentes, métodos y primeros resultados», Revista de Geografia, 30-31, 1996-1997, pp. 69-96.

- «Climatic variations in the Iberian Peninsula during the late Maunder Minimum (AD 16751715): an analysis of data from rogation ceremonies», The Holocene, 7, 1, 1997, pp. 105111.

BARRIENDOS, M. y DANNECKER, A.: «La sequía de 1812-1824 en la costa central catalana. Consideraciones climáticas e impacto social del evento», en Raso, J.M. y Martín Vide, J. (eds.): La climatología española en los albores del siglo XXI, Oikos-Tau, Barcelona, 1999, pp. 53-62.

Barriendos, M. y MARTín VIDE, J.: «Secular Climatic Oscillations as Indicated by Catastrophic Floods in the Spanish Mediterranean Coastal Area (14th-19th Centuries)», Clinatic Change, 38, 1998, pp. 473-491.

Barriendos, M.; Peña, J. C.; Martín Vide, J.; JONSSON, P.: «The Winter of 1788-1789 in the Iberian Peninsula from meteorological reading observations and proxy-data records», Actas del Congreso Giuseppe Toaldo e il Suo Tempo (1719-1797). Scienza e Lumi tra Veneto ed Europa, Padova, 2000, pp. $921-942$.

BARRIENDOS, M.: «LOS riesgos climáticos a través de la historia: avances en el estudio de episodios atmosféricos extraordinarios», en AYALA-CARCEDO, F. J. y OLCINA, J.: Riesgos naturales, Ariel, Barcelona, 2002, cap. 31, pp. 549-562.

Barriendos, M. y Llasat, M. C.: «The Case of the 'Maldá Anomaly in the Western Mediterranean Basin (AD 1760-1800): An Example of a Strong Climatic Variability», Climatic Change, 61, 2003, pp. 191-216.

Bentabol, H.: Las aguas de España y Portugal, Vda. e Hijos de M. Tello, Madrid, 2a. ed., 1900. 
BRADLEY, R. S. y JONES, P. D. (dirs.): Climate Since A.D. 1500, Routledge, Londres, 1992.

Brazdil, R.; Glaser, R.; Pfister, C.; Antoine, J. M.; BARriendos, M.; CAMufFo, D.; DeutsCH, M.; ENZI, S.; GUIDOBONI, E.; RODRIGO, F. S.: «Flood events of selected rivers of Europe in the Sixteenth Century», Climatic Change, 43, 1999, pp. 239-285.

BRU, F. M.: Fulls d'història de la vila de Tivissa i del seu territori antic, Aymá, S.L., Tarragona, 1955.

FERnÁndez Domingo, D.: Anales o Historia de Tortosa, desde su fundación hasta nuestros dias, Jaime Jepús, Barcelona, 1867.

Font Tullot, I.: Historia del clima de España. Cambios climáticos y sus causas, Instituto Nacional de Meteorología, Madrid, 1988.

Fontana TARRATS, J. M.: Entre el cardo y la rosa. Historia del clima en las Mesetas, Madrid, 1971-1977, 269 pp. Obra inédita, mecanografiada.

- Historia del clima en Cataluña. Noticias antiguas, medievales y en especial de los siglos XV, XVI y XVII, Madrid, 1976, 248 pp. Obra inédita, mecanografiada.

- Historia del clima del Finis-Terrae gallego, Madrid, 1977, 127 pp. Obra inédita, mecanografiada.

- Historia del clima en el litoral mediterráneo: Reino de Valencia más Provincia de Murcia, Javea, 1978, 206 pp. Obra inédita, mecanografiada.

Fontana TARrats, J. M.; Miró-Granada, J. y Vidal, J. J.: El clima de Baleares, hoy y ayer: 1450-1700, Madrid, 1974-1975, 104 pp. Obra inédita, mecanografiada.

García Herrera, R.; Macias, A.; Gallego, D.; Hernández, E.; Gimeno, L. y Ribera, P.: «Reconstruction of the precipitation in the Canary Islands for the period 1595-1836», Bulletin of the American Meteorological Society, 81, 1037-1039, 2003, pp. 68-77.

GIRALT, E.: «En torno al precio del trigo en Barcelona durante el siglo XVI», Hispania, 70-73, 18, Madrid, 1958, pp. 38-61.

Glaser, R.; Brazdil, R.; Pfister, C.; Dobrovolny, P.; Barriendos, M.; Bokwa, A.; CaMUfFo, D.; KoTYZA, O.; LiMANOWKA, D.; RACZ, L.; Rodrigo, F. S.: «Seasonal Temperature and Precipitation fluctuations in Selected parts of Europe during the Sixteenth Centurys, Climatic Change, 43, 1999, pp. 169-200.

Grove, J. M.: The Little Ice Age, Routledge, Londres, 1988.

LE ROY LADURIE, E.: Histoire du climat depuis l'an mil, Flammarion, París, 1967.

Luterbacher, J.; XoPlaki, E.; Dietrich, D.; Rickli, R.; JACOBEIT, J.; BeCk, C.; Gyalistras, D.; SCHMUTZ, C.; WANNER, H.: «Reconstruction of sea level pressure fields over the Eastern. North Atlantic and Europe back to 1500», Climate Dynamics, 18, 2002, pp. 545-561.

MARTIN VIDE, J. y BARRIENDOS, M.: «The use of rogation ceremony records in climatic reconstruction: a case study from Catalonia (Spain)», Climatic Change, 30, 1995, pp. 201-221.

PFISTER, C.: Klimageschichte der Schweiz 1525-1860. Das Klima der Schweiz von 1525-1860 und seine Bedeutung in der Geschichte von Bevölkerung und Landwirtschaft, Academica Helvetica, n. 6, Verlag Paul Haupt, Bern, 1988.

PFISTER, C.: Wetternachhersage: 500 Jahre Klimavariationen und Naturkatastrophen, Verlag Paul Haupt, Bern, 1999. 
Pfister, C.; Brazdil, R.; Glaser, R.; Barriendos, M.; Camuffo, D.; Deutsch, M.; DobroVOLNY, P.; ENZI, S.; GUIDOBONI, E.; KOTYZA, O; MIlTTZER, S.; RACZ, L.; RODRIGO, F. S.: «Documentary evidence on Climate in Sixteenth Century Europe», Climatic Change, 43, 1999 , pp. 55-110.

Rico Sinobas, M.: Memoria sobre las causas meteorologico-fisicas que producen las constantes sequias de Murcia y Almeria, señalando los medios de atenuar sus efectos, D.S. Compagni, Madrid, 1851.

Rodrigo, F. S.: Cambio climático natural. La Pequeña Edad del Hielo en Andalucía. Reconstrucción del clima histórico a partir de fuentes documentales, Departamento de Física Aplicada, Universidad de Granada. Tesis doctoral inédita, 1994.

Stothers, R. B.: «The great Tambora eruption in 1815 and its aftermath», Science, 224, 4654, 1984, pp. 1191-1198.

\section{AGRADECIMIENTOS}

Este trabajo ha sido realizado dentro del marco de un contrato de investigación del Programa «Ramon y Cajal» y del proyecto RAMSHES (REN2002-04584-C04-03/ CLI), ambos del Ministerio de Educación y Ciencia. 